\title{
Rauvolfia anomala, uma nova espécie de Apocynaceae da Chapada dos Guimarães, Mato Grosso, Brasil
}

\author{
Rauvolfia anomala, a new species of Apocynaceae \\ from Chapada dos Guimarães, Mato Grosso, Brazil
}

\author{
Alessandro Rapini ${ }^{1,4}$, Ingrid Koch ${ }^{2}$ \& André Olmos Simões ${ }^{3}$
}

\begin{abstract}
Resumo
Uma nova espécie de Apocynaceae, Rauvolfia anomala Rapini \& I. Koch, é descrita e ilustrada. Ela foi encontrada em cerrado-anão, na Chapada dos Guimarães, estado do Mato Grosso, simpatricamente a $R$. weddelliana. Aparentemente, as duas espécies são proximamente relacionadas, mas podem ser facilmente distinguidas pelas flores, cuja corola é esverdeada, com lobos mais longos que o tubo em $R$. anomala, enquanto em $R$. weddelliana ela é avermelhada, com lobos mais curtos que o tubo. A nova espécie apresenta um polimorfismo floral surpreendente e pode se tratar de um novo exemplo de dioicia no gênero. Esta é a primeira espécie de Rauvolfia com distribuição restrita registrada para o Mato Grosso. Palavras-chave: dioicia, neotrópicos, Rauvolfioideae, Região Centro-Oeste.
\end{abstract}

\begin{abstract}
A new species of Apocynaceae, Rauvolfia anomala Rapini \& I. Koch, is described and illustrated. It was found in low savanna of Chapada dos Guimarães, Mato Grosso state, sympatric with $R$. weddelliana. The two species seem to be closely related, but can be easily distinguished by the flowers, whose corolla is greenish, with lobes longer than the tube in $R$. anomala, or reddish with lobes shorter than the tube in $R$. weddelliana. The new species has remarkable floral polymorphism and possibly represents a new example of dioicy in the genus. This is the first species of Rauvolfia with narrow distribution reported to Mato Grosso.

Key words: dioicy, Neotropics, Rauvolfioideae, Central-West Region.
\end{abstract}

\section{Introdução}

Rauvolfia L. (Apocynaceae) é um gênero essencialmente pantropical, porém sem espécies nativas na Austrália. Inclui cerca de 65 espécies, com centro de diversidade nas Américas; são 37 espécies neotropicais, sendo 26 exclusivamente sul-americanas, sete da América Central, incluindo as Antilhas, e quatro representadas nas duas porções (para a revisão das espécies americanas, veja Rao 1956 e Koch 2002). O gênero tem atraído a atenção principalmente por causa de seus compostos químicos (especialmente os alcalóides indólicos) e suas propriedades farmacológicas, com espécies utilizadas no tratamento de desarranjos intestinais, hipertensão, distúrbios mentais e como antídoto para veneno de cobra (e.g. Bein 1956; Woodson et al. 1957). São plantas lenhosas, geralmente arbustos a arvoretas, com folhas e ramos verticilados, e coléteres na região nodal. As flores são hipocrateriformes, tubulosas ou urceoladas, em inflorescências cimosas, com carpelos total ou parcialmente fundidos e um disco nectarífero na base, rodeando o gineceu. Os frutos são drupáceos, com o desenvolvimento de um ou dois carpídios monospérmicos.

No Brasil, são registradas 19 espécies de Rauvolfia, 10 delas endêmicas, distribuídas principalmente nas Regiões Norte (10 espécies/2

\footnotetext{
Universidade Estadual de Feira de Santana, Depto. Ciências Biológicas. Av. Cidade Universitária s/n, 44036-900, Feira de Santana, BA, Brasil.

${ }^{2}$ Universidade Federal de São Carlos (UFSCAR), Campus Sorocaba. Rod. João Leme dos Santos, km 110, SP 264, 18052-780, Sorocaba, SP, Brasil.

${ }^{3}$ Universidade de São Paulo, Escola de Artes, Ciências e Humanidades (EACH), Av. Arlindo Bettio 1000, 03828-000, São Paulo, SP, Brasil.

${ }^{4}$ Autor para correspondência: rapinibot@yahoo.com.br
} 
endêmicas) e Nordeste (7 spp./5 end.), além de $R$. selowii Müll. Arg. ocorrendo nas Regiões Sul e Sudeste e $R$. pruinosifolia I. Koch \& Kin.-Gouv. em Minas Gerais. No Mato Grosso, apenas três espécies haviam sido registradas, todas com ampla distribuição: $R$. ligustrina Roem. \& Schult., com flores de corola alva, ocorre em vários ambientes, preferencialmente secos, na América do Sul e na América Central; R. sprucei Müll. Arg., com flores de corola alva, manchada de púrpura nos lobos, ocorre em capoeiras da região amazônica, chegando até o Peru e a Venezuela; e $R$. weddelliana Müll. Arg., com flores de corola avermelhada a vinácea, ocorre em campos e cerrados, alcançando o Paraguai (Koch 2002, Koch et al. 2007). Em visita recente à Chapada dos Guimarães, no entanto, uma nova espécie de Rauvolfia foi encontrada, aqui descrita como R. anomala Rapini \& I. Koch. Ela apresenta uma plasticidade floral surpreendente e é a primeira espécie de Rauvolfia com distribuição restrita registrada para o estado.

\section{Material e Métodos}

Foram examinadas as coleções de Rauvolfia depositadas nos herbários A, ALCB, B, BHCB, BM, BR, C, CEPEC, CGMS, COL, CR, CTES, CVRD, EAC, ESA, F, FUEL, G, GH, HRB, HRCB, HUEFS, IAC, IAN, INPA, K, LPAG, M, MBM, MBML, MEXU, MG, MO, NY, R, RB, S, SI, SP, SPF, SPSF, TEPB, UEC, UFMT, US, W, Z (siglas conforme Thiers 2010). A terminologia utilizada na descrição morfológica está baseada em Radford et al. (1974) e Stearn (1998). As medidas e ilustrações de detalhes florais foram realizadas com auxílio de microscópio estereoscópico Leica MZ8 com câmara clara acoplada.

\section{Resultados e Discussão}

Rauvolfia anomala Rapini \& I. Koch, sp. nov. Tipo: BRASIL. MATO GROSSO: Chapada dos Guimarães, Cidade de Pedra, 15¹8'06”'S, 5550'07’'W, 28.I.2008, fl. e fr., A. Rapini, P.L. Ribeiro \& U.C.S. Silva 1887 (holótipo HUEFS!; isótipos HUEFS!, K!, MO!, RB!, UB!, UEC!).

Figs. 1-3

A Rauvolfia weddelliana Müll. Arg. floribus cum corolla viridescenti (non vinacea) et lobis corollae quam tubo longioribus (vice brevioribus) differt.

Arbusto ereto, ca. $50 \mathrm{~cm}$ alt., látex branco, ramos 2-4 por verticilo, glabros, os mais jovens castanhos, esparsamente lenticelados, sem catafilos evidentes, coléteres digitiformes ao longo de toda a região nodal. Folhas sésseis, 3 ou 4 por nó, distribuídas ao longo dos ramos floríferos, 6-8,5× 2,5-4 cm, quase iguais entre si, eventualmente 1 menor (ca. 3,5 × 1,5 cm), elípticas, agudas a acuminadas no ápice, atenuadas na base, revolutas na margem, levemente buladas, membranáceas, glabras; nervação broquidódroma, a nervura central canaliculada na face adaxial, proeminente na abaxial, 14-17 pares de nervuras laterais, ca. $75^{\circ}$ em relação à nervura central, sutilmente emersas na face adaxial, proeminentes na abaxial. Pleiocásios axilares, 2 ou 3 por nó, com 6 a ca. 50 flores, subcorimbiformes, 5-10 cm compr., com 2-5 ordens de ramificação e coléteres digitiformes nos artículos; pedúnculo 3-5 cm compr.; brácteas, 2-2,2 × 1-2 $\mathrm{mm}$, triangulares a lanceoladas, margem glandular no terço basal, glabras; bracteólas 1-1,5 × 0,5-0,7 $\mathrm{mm}$, triangulares, margem glandular no terço basal, glabras; pedicelo 4,5-7 mm compr. Cálice verde, glabro, sem coléteres; lobos 1,5-2,3(2,7) ×0,7-1,1 $\mathrm{mm}$, ovados a lanceolados, às vezes subiguais, inteiros, imbricados. Corola esverdeada, geralmente com lobos verdes e tubo creme, hipocrateriforme; tubo 2-2,8×1,6-2,2 mm compr., levemente constrito na fauce, puberulento na parte interna, com tricomas retos a partir da porção distal do terço basal, mais longos, curvos e moniliformes na região de inserção das anteras e acima dela; lobos 3-5,8 × 1-4,4 mm, elípticos a obovados ou espatulados, revolutos, eretos a levemente oblíquos, imbricados. Anteras 1,2-1,4×0,3-0,5 mm, triangulares, acuminadas no ápice, com as tecas separadas na base, subssésseis, dorsifixas, inseridas na porção mediana do tubo, com ápice alcançando a fauce da corola. Ovário com carpelos geralmente livres na porção mediana, 0,50,6 mm compr.; estilete $0,25-0,3(-0,7)$ mm compr.; cabeça do estilete $0,5-0,6 \mathrm{~mm}$ compr., fusiforme, com dois apêndices apicais, eventualmente não diferenciada, então estilete até 1,7 mm compr.; disco nectarífero 0,1-0,2 mm, anelar. Frutos verdes, 1 drupa ou 2 carpídios drupáceos sincárpicos, ca. 1-1,2 × 0,5-2 cm compr., elípticos (drupa) ou cordiformes (drupáceo), epicarpo liso, endocarpo rugoso.

Rauvolfia anomala é facilmente reconhecida pelo hábito subarbustivo e pelas flores esverdeadas, com lobos da corola mais longos que o tubo. As flores apresentam-se polimórficas, frequentemente incompletas e por vezes estéreis, com os órgãos florais, a exceção do cálice, transformados em apêndices foliáceos (Figs. 2d, 3d). A maioria das flores examinadas não apresenta a cabeça do estilete completamente formada (Fig. 2f, i-l) e foram 


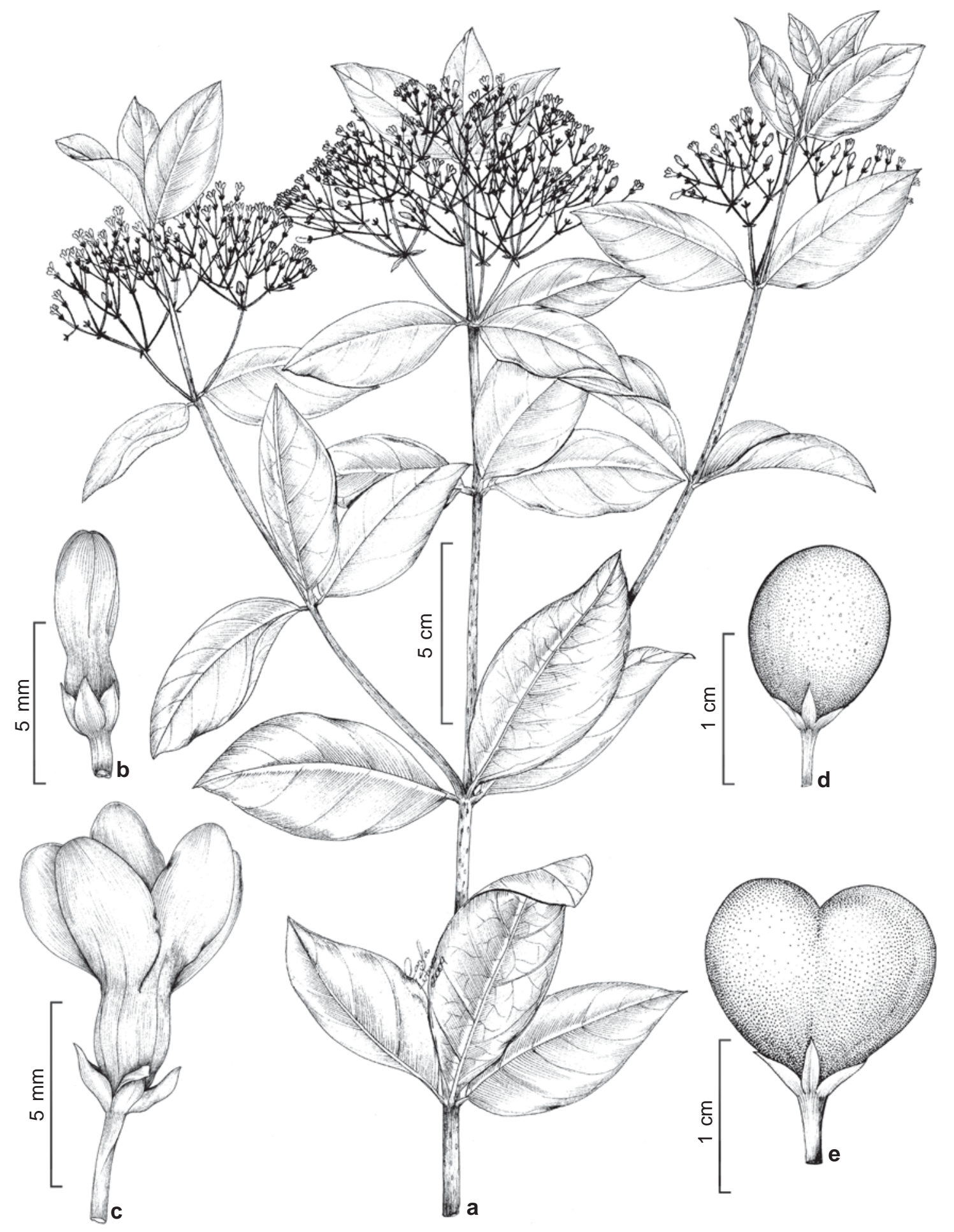

Figura 1 - Rauvolfia anomala Rapini \& I. Koch. - a. ramo com flores; b. botão; c. flor; d. fruto drupa; e. fruto drupáceo com dois carpídios sincárpicos (Rapini et al. 1887).

Figure 1 - Rauvolfia anomala Rapini \& I. Koch. - a. branch with flowers; b. flower-bud; c. flower; d. fruit (drupe); e. fruit drupaceous, with two syncarpic carpids (Rapini et al. 1887). 

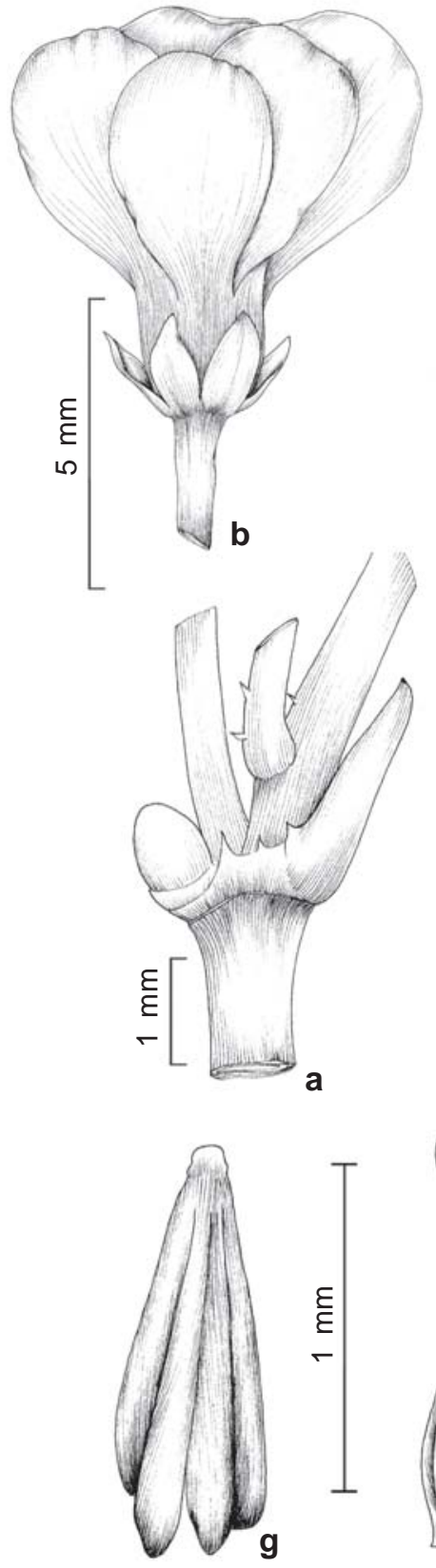
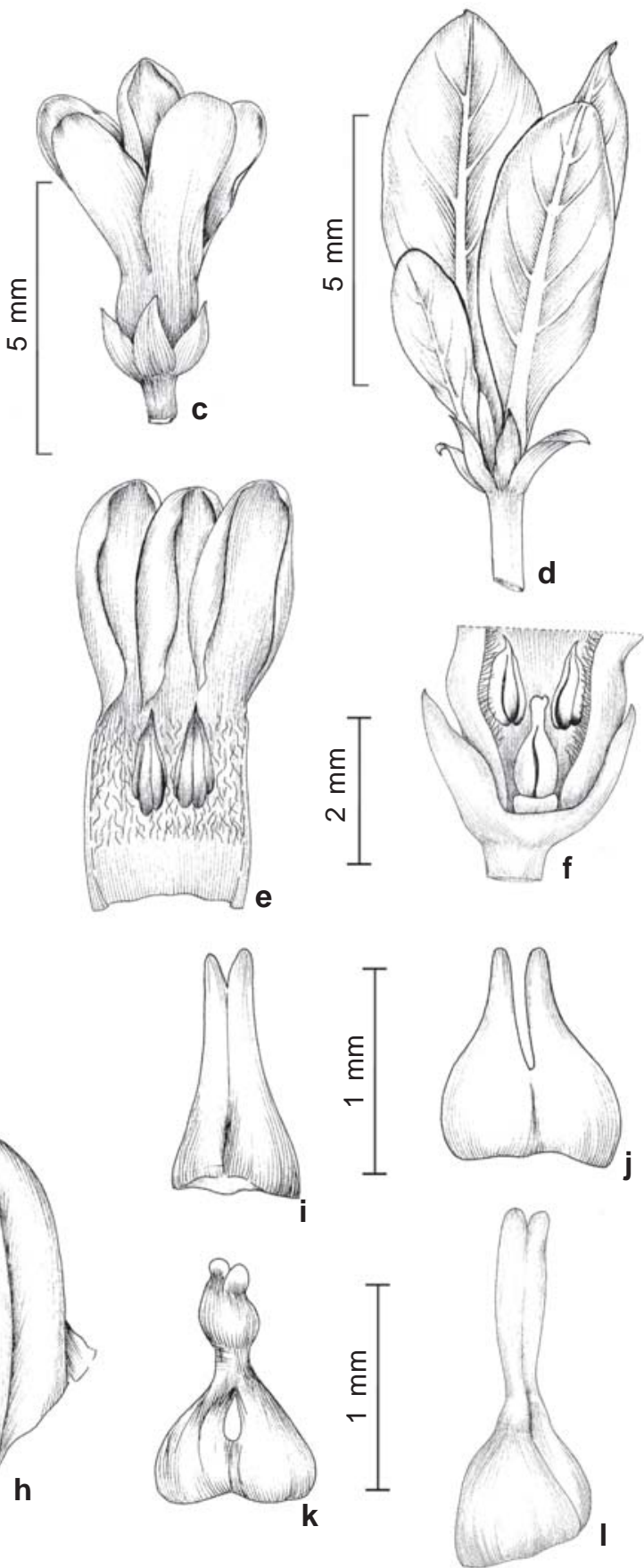

Figura 2 - Rauvolfia anomala Rapini \& I. Koch - a. detalhe de um artículo da inflorescência; b-c. flor, mostrando variação floral; d. 'flor', com órgão internos transformados em apêndices foliáceos; e. parte da porção mediana da corola aberta, mostrando dois estames e o indumento; f. secção longitudinal da porção basal da flor mostrando internamente o gineceu, com o disco nectarífero na base, dois estames e o indumento da corola; g. antera, vista frontal; h. antera, vista lateral; i-1. gineceu, mostrando a variação encontrada na população (Rapini et al. 1887).

Figure 2 - Rauvolfia anomala Rapini \& I. Koch - a. detail of an inflorescence node; b-c. flower, showing floral variation; d. 'flower', with internal organs converted into leafy appendix; e. part of open corolla, showing two stamens and the indumentum; f. longitudinal section of the basal portion of the flower, showing the gynoecium inside, with nectariferous disk at the base, two stamens and the corolla indumentum; g. anther, frontal view; h. anther, lateral view; i-l. gynoecium, showing variation into the population (Rapini et al. 1887). 

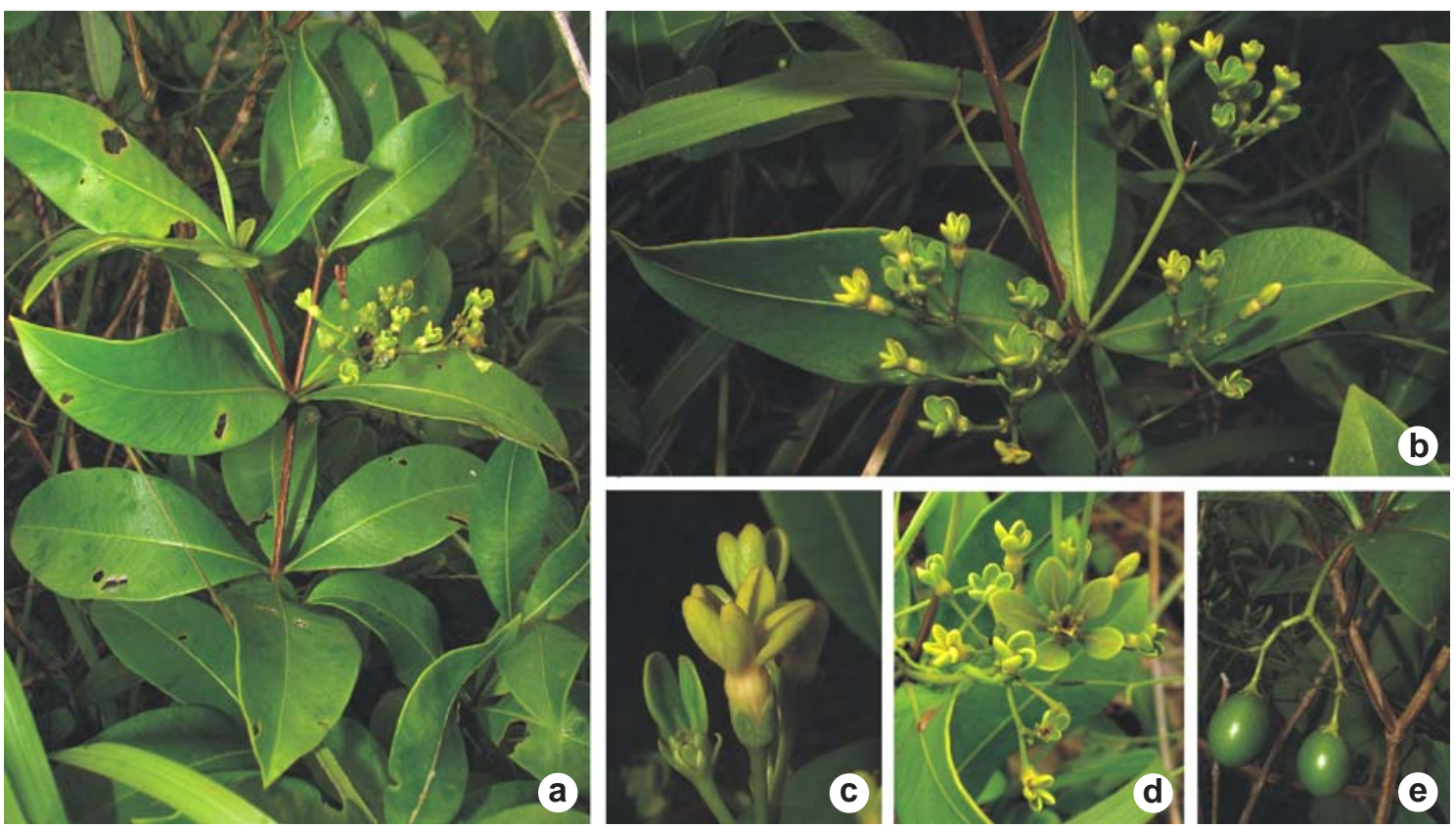

Figura 3 - Rauvolfia anomala Rapini \& I. Koch - a. ramo com flores; b. nó com folhas e inflorescências; c. flor; d. inflorescência com uma das flores apresentando a corola transformada em cinco apêndices foliáceos; e. infrutescência com drupas (Rapini et al. 1887).

Figure 3 - Rauvolfia anomala Rapini \& I. Koch - a. branch with flowers; b. node with leaves and inflorescences; c. flower; d. inflorescence with one of the flower presenting the corolla converted into five leafy appendix; e. infrutescence with drupes (Rapini et al. 1887).

observadas também flores com anteras vazias, indicando a possibilidade de haver diocia na população. Este sistema reprodutivo foi constatado em $R$. sellowii, mas por ser críptico no gênero pode estar passando despercebido em outras espécies de Rauvolfia (Koch et al. 2002). Análises morfológicas e reprodutivas mais detalhadas nessa população, no entanto, ainda são necessárias para se confirmar a hipótese de dioicia em de R. anomala.

A espécie foi encontrada em 'cerrado-anão', vegetação baixa e densa, dominada por gramíneas e subarbustos com cerca de $50 \mathrm{~cm}$ de altura, sobre solo arenoso, em platô a cerca de $700 \mathrm{~m}$ de altitude. Ela ocorre em simpatria com uma população de $R$. weddelliana, espécie com a qual parece estar mais proximamente relacionada. Essas duas espécies foram encontradas com flores e frutos em janeiro e são facilmente distinguidas pela cor e forma da corola (em $R$. weddelliana, vinácea e com lobos bem mais curtos que o tubo).

Embora classificações infragenéricas tenham sido propostas para Rauvolfia (e.g. Rao 1956), elas parecem inconsistentes em alguns casos (Koch 2002) e a relação entre as espécies do gênero ainda carece de estudos filogenéticos. Caso a proximidade filogenética entre $R$. anomala e $R$. weddelliana seja confirmada, elas poderão diagnosticar um exemplo claro de cladogênese na ausência de isolamento geográfico ('especiação simpátrica'). Essa ruptura entre as duas linhagens pode ter sido facilitada pela rápida divergência de $R$. anomala, possivelmente proporcionada por modificações mediadas por genes reguladores da identidade floral, o que pode ser evidenciado pela instabilidade na morfologia floral da espécie e pela presença de flores anormais (Meyerowitz et al. 1989), com órgãos transformados em folhas (Goto et al. 2001). A existência de vários indivíduos na população e a produção de frutos indicam que estas características não parecem ser aberrações esporádicas, nem a população representar um híbrido estéril.

A Chapada dos Guimarães representa uma área de transição entre a Amazônia e o Cerrado e abriga outras nove espécies microendêmicas, com área de ocorrência de até 10.000 km², algumas delas sem coletas há mais de um século, como Dasyphyllum retinens (S. Moore) Cabrera (Asteraceae) e Kielmeyera tricophora Saddi (Clusiaceae) (Giulietti 
et al. 2009). Dentre as Apocynaceae da região, destaca-se Nephradenia filipes Malme, conhecida apenas pelo material-tipo, coletado por Malme em 1894, próximo ao Morro de São Gerônimo, atualmente parte do Parque Nacional da Chapada dos Guimarães. Esta espécie foi coletada novamente, mais de um século após seu primeiro e, até então, único registro, próximo à população de $R$. anomala, na Cidade de Pedra, área turística fora do Parque Nacional. Nossos dados ainda são insuficientes para classificar essa nova espécie quanto ao grau de ameaça, mas seu registro amplia o número de espécies raras da Chapada dos Guimarães e reafirma a região como uma área chave de biodiversidade.

\section{Agradecimentos}

Agradecemos à chefia do Parque Nacional da Chapada dos Guimarães, por facilitar nosso acesso ao Parque e seus arredores, e a Cássio van den Berg o auxílio na diagnose em latim. Este estudo faz parte do projeto em diversidade e filogenia de Apocynaceae, coordenado pelo primeiro autor e financiado pela Fapesb. O primeiro autor é bolsista PQ-2 do CNPq.

\section{Referências}

Bein, H.J. 1956. The pharmacology of Rauwolfia. Pharmacological Review 8: 435-483.

Giulietti, A.M.; Rapini, A.; Andrade, M.J.G.; Queiroz, L.P. \& Silva, J.M.C. (orgs). 2009. Plantas raras do Brasil. Conservação Internacional \& Universidade Estadual de Feira de Santana, Belo Horizonte. 496p.
Goto, K.; Kyozuka, J. \& Bowman, J.L. 2001. Turning floral organs into leaves, leaves into floral organs. Current Opinion in Genetics \& Development 11: 449-456

Koch, I. 2002. Estudos das espécies neotropicais do gênero Rauvolfia L. (Apocynaceae). Tese de Doutorado. Universidade Estadual de Campinas, Campinas. 292p.

Koch, I.; Bittrich, V. \& Kinoshita, L.S. 2002. Reproductive biology and functional aspects of the floral morphology of Rauvolfia sellowii Müll. Arg. (Apocynaceae; Rauvolfioideae) - A report of dioecy in Apocynaceae. Botanische Jahrbücher für Systematik 124: 83-104.

Koch, I.; Bittrich V. \& Kinoshita, L.S. 2007. Taxonomic novelties in Rauvolfia (Apocynaceae, Rauvolfioideae) from Brazil. Novon 17: 462-471.

Meyerowitz, E.M.; Smyth, D.R. \& Bowman, J.L. 1989. Abnormal flowers and pattern formation in floral development. Development 106: 209-217

Radford, A.E.; Dickison, W.C.; Massey, J.R. \& Bell, C.R. 1974. Vascular plant systematics. Harper \& Row, New York. 891p.

Rao, A.S. 1956. A revision of Rauvolfia with particular reference to the American species. Annals of the Missouri Botanical Garden 43: 253-355.

Stearn, W.T. 1998. Botanical latin. 4 ed. Timber Press, Portland. 546p.

Thiers, B. 2010. Index Herbariorum: A global directory of public herbaria and associated staff. New York Botanical Garden's Virtual Herbarium. Disponível em <http:// sweetgum. nybg.org/ih/>. Acesso em 13 abril 2010.

Woodson R. E.; Youngken, H. W.; Schittler, E. \& Schneider, J.A. 1957. Rauwolfia: Botany, pharmacognosy, chemistry, and pharmacology. Little, Brown, and Co., Boston. 149p. 